\title{
Interruption of autoimmunity for thyroid eye disease: B-cell and T-cell strategy
}

\author{
Diego Strianese ${ }^{1} \cdot$ Francesca Rossi $^{2}$
}

Received: 18 October 2018 / Accepted: 25 October 2018 / Published online: 4 January 2019

(C) The Royal College of Ophthalmologists 2019

\begin{abstract}
Recent new insights into the molecular basis of thyroid eye disease have led to the use of more specific therapies such as monoclonal antibodies This review explores the traditional immunosuppressant therapy for TED, highlighting the basis for emergent recent medications, possible treatment options and, eventually possible new general recommendation for management of TED. Data has been retrieved from the literature searching on Pubmed. Steroid therapy remains the first line therapy for moderate/severe and severe vision threatening TED The use of some traditional nonspecific immunosuppressant such as mycophenolate, cyclosporine and azathioprine seems useful in combination with steroid therapy to achieve stable results in the long term; methotrexate is useful as steroid-sparing medications and in steroid resistant or intolerant patients. In recent years, many scientific reports have showed the effectiveness of biological immunosuppressive agents in the management of TED. Etanercept, adalimumab, and tocilizumab have shown to be effective in reduction of the inflammatory signs with the possible advantage to prevent relapse of the disease. Particularly Tociliuzumab seems very effective as second line therapy, after steroid failure. Teprotumumab may control the disease activity and it seems to be very effective in preventing severity disease progression. Infliximab might be useful in severe TED with optic nerve compression resistant to steroid and decompression. Indeed, the actual incidence of adverse effects is not well assessed yet, therefore the use should be limited at those cases that really need an alternative therapy to steroid, handled by an expert multidisciplinary team.
\end{abstract}

\section{Introduction}

Pathological changes of Thyroid eye disease (TED) in the orbit appear to involve both the extraocular muscles and the orbital fat compartments, with radiological imaging indicating most patients have a mixture of both extraocular muscle enlargement and orbital fat expansion [1]. Proptosis is due to expansion of orbital tissue within the unyielding confines of the bony orbit. The consequent increase in orbital pressure can also lead to venous outflow congestion and chronic periorbital oedema [2].

Diego Strianese

dstrianese@kkesh.med.sa

strianes@unina.it

1 Department of Neuroscience, University of Naples -Federico II, Naples, Italy, and - Orbital Unit-King Khaled Eye Specialist Hospital Riyadh, Saudi Arabia

2 Department of Translational Medical Sciences and Center for Basic and Clinical Immunology Research, University of Naples Federico II, Naples, Italy
The precise pathogenesis of this thyroid-associated ophthalmopathy remains incompletely understood, although autoimmune mechanisms clearly play a part. Treatments for TED have largely been non-specific and involved immunosuppression targeting the adaptive immune system. While effective, these broad-spectrum approaches may lead to significant adverse effects, including increased risk of infections and toxicity to non-immune cells. More specific therapies targeting individual cell populations refining the targets, sparing components of the adaptive immune system not involved, could lead to a more acceptable risk: benefit ratio.

Considerable progress has been made in unravelling the molecular mechanisms involved in the autoimmune attack of orbital tissues, which has led to several innovative therapies, including drugs that target orbital fibroblast receptors or inflammatory cytokines [3].

\section{B-cell and T-cell}

Immunological memory of the adaptive immune system plays an important role in the defence against infectious, 
since it allows the immune response to a previously recognised antigen [4]. This particular attribute may, however, be an effective target in autoimmune disorders, in which the ability of the immune system to recognise an autoantigen more readily would be detrimental.

Immunological memory in the humoral arm of the adaptive immune system is mediated through long-lived memory B cells and sustained antibody titres produced from long-lived plasma cells [5].

These cells are produced primarily in the germinal centres of secondary lymphoid organs; however, the precise mechanisms leading to differentiation from naive $\mathrm{B}$ cells to memory B cells or long-lived plasma cells are unclear [6].

Memory B cells provide enhanced antibody production when restimulated and are characterised by isotype switching and affinity maturation [7].

As well as the production of antibodies, memory B cells also play important roles in autoimmunity through cytokine production and antigen presentation to $\mathrm{T}$ cells [8].

Long-lived plasma cells also provide humoral immunological memory and could serve as a source of pathogenic antibodies in autoimmune disease. Long-lived plasma cells can persist for several years and have high expression of CXCR4 [9].

They require several different growth factors for survival, such as IL-6, ligands for CD44 and CD28-B7 interactions [10].

T cell infiltrates in TED orbital tissues are predominantly CD4+, with some studies suggesting presence of both $\mathrm{CD} 8+$ and $\mathrm{CD} 4+\mathrm{T}$ cells. Th1-like cytokine profile predominates in TO retrobulbar tissue [11-14].

Th1-like cytokine expression profile consisting of interferon (IFN)- $\gamma$, tumour necrosis factor (TNF)- $\alpha$, IL- $1 \beta$ and IL-6 has been detected mainly in TO extraocular muscles, whereas IL-4 and IL-10, Th2-type cytokines were detected predominantly in orbital fat [15]. Predominance of $\mathrm{T}$ cell subsets is also disease duration dependent, with Th1 cells dominating in the active phase of TO, shifting towards Th2 cells in the late phase [16].

\section{TSH and IGF-1 receptors}

Recent and old evidence confirm that TSH receptor play a central role in the pathological cascade of TED. Particularly the breaking of self-tolerance to TSH Receptor (TSHR) on thyroid epithelial cells, resulting in TSHR stimulating antibodies inducing thyrotoxicosis, is well demonstrated in TED [17, 18].

TSHR signals has two G-protein mediated pathways: the adenylyl cyclase/cAMP pathway and the PI3K/AKT/mTOR pathway [19].

The first evidence of TSHR as an autoantigen came from identifying TSHR expression in retro-orbital tissue in cultured orbital fibroblast from patients with TED by PCR and liquid hybridisation [20-22].

With improvement of TSHR assays, both thyroid binding inhibiting Ig (TBI) and thyroid stimulating Ig (TSI) TSHR titres are shown to be highly and significantly correlated with activity and severity of TO [23].

More recently, new evidence have found a relevant role of Insulin Growth Factor-1Receptor (IGF-1R) in TED. IGF$1 \mathrm{R}$ is a ubiquitous cellular surface receptor involved in diverse cellular responses including modulation of apoptosis, enhancing cell survival, growth and cellular proliferation, cell motility and migration [24, 25].

Evidence suggests IGF1/IGF-1R is involved in the pathogenesis of TO, but the autoantigenic role of IGF-1R remains controversial. IGF-1R regulates lymphocyte trafficking in the orbit, HA synthesis, adipogenesis and defines T-lymphocyte and B-lymphocyte phenotypes and function [26].

The bridge between immune cells and orbital fibroblasts and the molecular pathways leading to proliferation and differentiation of orbital fibroblast, the secretion of HA, the adipogenesis.

\section{Fibroblast}

Recent evidence suggests the orbital fibroblast is the key effector cell in TED [27]. Orbital fibroblasts not only proliferate and differentiate into myofibroblasts and adipocytes, but produce GAG in excess, undergo adipogenesis and actively interact with mononuclear cells, producing chemoattractants and cytokines, which ensure perpetuation of orbital inflammation [28-30].

Proliferation of orbital fibroblasts is activated by the interaction of autoantigens on fibroblasts with $\mathrm{T}$ cells by $\mathrm{T}$ cell receptor interaction with the Major histocompatibility complex class II (MHC II) molecules and by the CD40: CD154 signalling [29].

Co-culture of orbital fibroblasts with autologous $\mathrm{T}$ cells stimulates production of MHC II molecules and orbital fibroblasts dose-dependent proliferation. MHC II, CD40 and CD40 ligand (CD154) blocking antibodies completely inhibit proliferation of orbital fibroblasts [29].

Heterogenous presentations of TED could be due to cellular divergence of orbital fibroblasts within the orbit [30].

The fibroblast populations in the orbit are phenotypically heterogeneous and differ with regard to surface glycoprotein, production of pro-inflammatory cytokines and cell surface receptor expression [31-33].

\section{Hyaluronic acid synthesis}

Both orbital fibroblast surface receptors for TSHR and IGF$1 \mathrm{R}$ appear to stimulate HA synthesis. TSHR activation 
alone is sufficient to upregulate HAS1 and HAS2 expression and HA production via cyclic adenosine monophosphate (cAMP) and AKT/phophoinositide 3 kinase (PI3K) signalling [34-36].

Alternative IGF-1R pathways are also involved in HA synthesis as described by the substantial equivalent increase in HA synthesis in orbital fibroblasts by immunoglobulin $\mathrm{G}$ (IgG) from GD and IGF-1 [37, 38].

\section{Adipogenesis}

De novo adipogenesis is enhanced in TO as evidenced by increased expression of adipocyte-specific genes leptin, adiponectin, fatty acid synthase, adipocyte fatty acid binding protein (AP2) and PPAR- $\gamma$ mRNA.

Both TSHR and IGF-1R are involved in adipogenesis, indeed they share the same intracellular AKT/PI3K signalling. The close relationship between TSHR and IGF-1R in triggering adipogenesis in TO perhaps could be explained by co-localisation of these two receptors on orbital fibroblasts [24].

Stimulatory TSHR antibody increases phosphorylated AKT protein, cAMP levels and enhanced adipogenesis via the PI3K signalling cascade [39].

On the other hand, IGF-1 mediates proliferation and differentiation of human and murine 3T3-L1 pre-adipocytes into adipocytes [40, 41].

IGF-1 mediates its effect by binding to IGF-1R and induces phosphorylation of Src homology 2 domaincontaining protein (Shc) and insulin receptor substrate (IRS) and downstream AKT/PI3K pathway [41, 42].

IGF-1 uses Shc/IRS-1 to activate MAPK/ERK signalling in proliferating 3T3-L1 pre-adipocytes. Inhibiting MAPK by Shc proximal signalling switches off proliferation of pre-adipocytes and in turn permits differentiation into adipocytes with increased expression of PPAR- $\gamma$, LPL and AP2 [43].

\section{Interruption of the autoimmunity: immunosuppressive therapy}

Two types of immunosuppression can be described: nonspecific suppression and specific suppression. In nonspecific immunosuppression, the blocking agent prevents the immune system from attacking any antigen, but on the other side, nonspecific immunosuppression, break down the ability of the body to defend itself against infection (Fig. 1). In specific suppression, the blocking agent restricts the immune system from attacking one or a specific number of antigens. (Fig. 2)

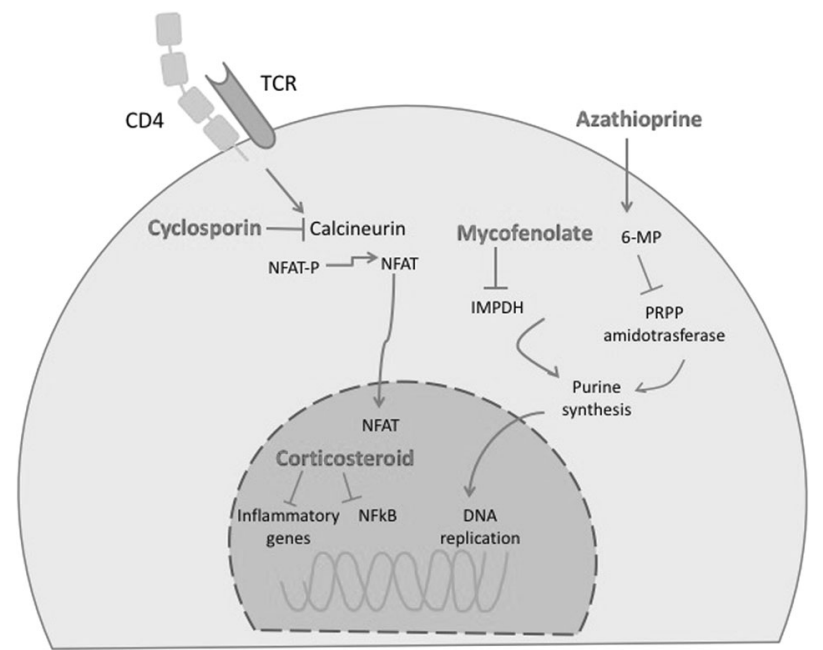

Fig. 1 Schematic representation the sites of effect of no-specific immunosuppressant

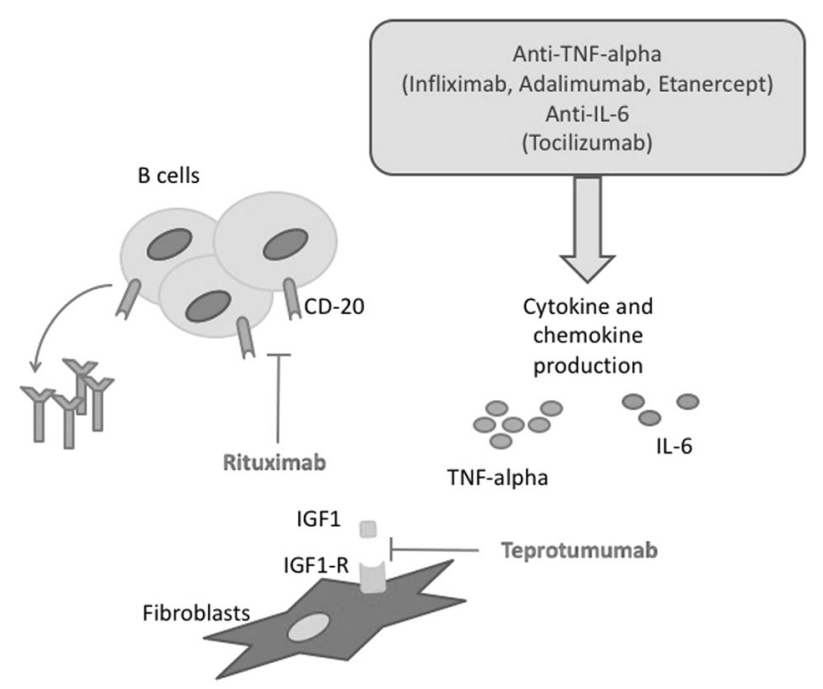

Fig. 2 Schematic representation of the targets of the site-specific immunosuppressant

\section{A) Nonspecific immunosuppressant}

Those agents can interrupt the autoimmunity interfering with several intracellular pathways of the immune cells resulting in a wide decrease of the immune response not site specific. Although they have been used since a long time, sometimes the mechanisms of action are still not fully understood.

1) Glucocorticoids are still the mainstay of TED therapy. Administration of high-dose intravenous steroids can halt lymphocyte recirculation and interfere with inflammation and with the release of autoantigen. 
The anti-inflammatory and immunosuppressive effects of glucocorticoids rely on several molecular mechanisms, which have been elucidated by basic research. Evidence indicates that the glucocorticoid receptor inhibits inflammation and immunology response through three mechanisms: direct and indirect genomic effects and nongenomic mechanisms. The direct effects on gene expression include the binding of glucocorticoid receptors to glucocorticoidresponsive elements; indirect effects are on gene expression through the interactions of glucocorticoid receptors with other transcription factors and in the so-called non-genomic pathways, the glucocorticoid receptor-mediated effects are on a second-messenger cascades. Unfortunately, because some of these mechanisms are also involved in physiologic signalling rather than inflammatory signalling, the therapeutic effects of glucocorticoids might be accompanied by clinically significant side effects [44].

Glucocorticoids can be administered via an oral, intravenous, retrobulbar, or subconjunctival route. Retrobulbar and subconjunctival application of steroids is not commonly performed due to side effects and lack of efficacy [45].

Current literature favours high dose systemic administration for severe active TED. A greater positive clinical response in $77 \%$ of patients receiving intravenous (IV) methylprednisolone treatment was reported vs. $51 \%$ of patients treated with oral prednisolone [46]. A similar response was also described for treatment of moderate active TED with $72 \%$ responding to IV steroids vs. $49 \%$ responding to oral steroids [47].

A prospective, single-blind randomised study evaluated cobalt radiation combined with steroid treatment, either administered systemically or locally by retrobulbar injection [48]. Clinical improvement was noted in both groups, but there was a significantly greater efficacy of systemic steroids compared to retrobulbar injection (60\% vs. $30 \%)$ in severe active TED. Thus, there is a general agreement that the optimal IV regimen for moderate to severe TED is weekly doses of $500 \mathrm{mg}$ for 6 weeks followed by $250 \mathrm{mg}$ weekly doses for a further 6 weeks. However, relapses after completion of treatment account for about $20 \%$ and compressive optic neuropathy (ON) can develop in $7.5 \%$ of patients [49].

Treatment response of pulse IV steroid therapy may be seen within 1-2 weeks. IV steroids are most effective in reducing inflammatory soft tissue findings and ocular motility dysfunction. However, rare cases that developed acute, severe liver failure during pulse steroid therapy have been documented [50]. The cumulative methylprednisolone dose in these cases was 10-24 g. IV steroid therapy may exacerbate underlying autoimmune liver disease. Therefore, it is advisable to limit the cumulative methylprednisolone dose to $6-8 \mathrm{mg}$ and identify patients at risk by evaluating liver morphology, viral markers, and autoantibodies prior to treatment. Seven deaths have been reported: 4 due to acute liver failure, 2 due to cerebrovascular disease, and 1 due to pulmonary embolism, occurring between 4 and 120 days after starting IV methylprednisolone. All but one of the patients who died had received a cumulative dose of more than $8 \mathrm{~g}$ [51]. Identified risk factors for adverse effects from IV methylprednisolone are dose, age older than 53 years, daily pulses, and pre-existing hepatitis [52].

In a 2011 review of IV methylprednisolone, 1045 patients showed a morbidity of $6.5 \%$ and mortality of $0.57 \%$ [53]. Acute liver damage, defined as an alanine aminotransferase increase exceeding four times the upper limit of normal, was reported in $1 \%$ of 376 patients receiving steroid therapy [53]. A cumulative dose of $4.5 \mathrm{~g}$ was recommended because it does not result in suppression of the hypothalamus-pituitary-adrenal axis [54]. Administration of alendronate could suppress steroid-induced bone resorption, which can occur in any patient receiving IV methylprednisolone [55].

2) Cyclosporine (CysA) is a lipophilic cyclic polypeptide, the drug is extracted from the soil fungus Beauverianivea. CysA inhibits calcineurin, preventing the secretion of interleukin- 2 by CD4+ T-lymphocytes, and thereby interfering with the expansion of lymphocyte clones. Acting on the amplification phase of the immune response, cyclosporine may prevent the recrudescence of the cycle of autoimmunity, being an ideal agent to maintain remission of TED.

A number of cytokines; particularly, TNF-alpha which is secreted by roaming CD4+ lymphocytes and tissue macrophages, drive fibroblasts to proliferate and secrete glycosaminoglycan, then collagen. Conveniently, TNF-alpha release from either source is inhibited by CysA making these also ideal agents to induce inhibition of the cicatricial phase of thyroid eye disease.

Results with cyclosporine as a single agent were rather conflicting but mostly non-satisfactory [56]. However, even though poorly effective as a single agent, cyclosporine might have a role, in association with glucocorticoids, in patients who do not respond to glucocorticoids alone [57]. In addition, the association of methylprednisolone $(10 \mathrm{mg} / \mathrm{kg} \mathrm{IV}$ repeated at $48 \mathrm{~h}$ intervals 3 times) and CysA with a starting dose $2 \mathrm{mg} / \mathrm{kg}$ twice daily, then tapered in 2 years, has been shown to be highly effective in a group of patients with optic nerve compression; with all patients recovering their premorbid visual acuities and visual fields and, with improvement of ocular motility, when initially impaired [58].

CysA may carry the risk of some side effects such as irreversible rise of the plasma creatinina or more frequently hypertension, hence while its use in transplanted patients or in severe autoimmune disorders is obviously worthwhile, the administration for TED patients must seriously take into account those complications. 
3) Azathioprine (AZA) is a cytostatic agent and it was the first medication to achieve widespread use in organ transplantation. It is a prodrug that is converted first to 6mercaptopurine (6-MP) and then to the corresponding nucleotide, thioinosinic acid, which through a false nucleotide incorporation inhibits purine synthesis necessary for the proliferation of cells. The site of action is direct on DNA.

AZA has not been shown to be of benefit as a single agent [59] but exhibits effectiveness when combined with radiation therapy or steroid [60,61]. Its major toxicity is bone marrow suppression. Nausea and vomiting are also encountered. In a non randomised study, combination of oral steroids with long-term oral AZA and orbital radiotherapy (20 Gy) appears to reduce morbidity in patients with active disease and particularly the subgroup with marked restrictive myopathy by improving diplopia and duction amplitude and decreases the need for rehabilitative surgery [61]. In a recent multicenter, double-blind, randomised controlled trial with a $2 \times 2$ factorial design conducted at six centres in the UK, results showed an improved clinical outcome at 48 weeks with azathioprine treatment, associated to steroid [62].

4) Mycophenolatemofetil (MMF) is an immune modulatory drug which inhibits the inosine monophosphate dehydrogenase, leading to inhibition of the de novo pathway for guanosine monophosphate synthesis, resulting in depletion the pool of guanosine-tri-phosphate and thereby inhibits the proliferation of lymphocytes. In a study of 74 patients with active moderate-to-severe TED who were randomised to receive either MMF or glucocorticoids, MMF group therapy showed a better Clinical Activity Score (CAS) response than glucocorticoid $(92.5 \%$ vs. $70.5 \%$ improved, $P<0.05)$ and a significantly improved rate of diplopia and proptosis at the 24th week $(90.4 \%$ and $68.8 \%$ improved, respectively). Disease reactivation was not observed in the patients treated with MMF but was observed in patients after glucocorticoid therapy. Adverse events occurred in 5\% of patients treated with MMF which were mild to moderate due to increased risk of infection [63].

5) Methotrexate is an immunosuppressive drug that inhibits dihydrofolate reductase enzyme, leading to the inhibition of the DNA, RNA, and protein synthesis. It has been shown to be effective as a sole treatment in patients who failed steroids or became steroid dependent. Two recent studies have confirmed that methotrexate provides steroid sparing effect in a subset of patients with TED. Fourteen patients with TED who were unable to discontinue prednisone therapy without disease recurrence received methotrexate, from $15 \mathrm{mg} /$ week orally to $20 \mathrm{mg} /$ week subcutaneously [64]. Five patients discontinued therapy for a lack of benefit or intolerance. Of the 9 patients who remained on methotrexate, all were able to discontinue prednisone completely after an average duration of 7.5 months. Improved visual acuity and partial improvement in ocular motility was achieved in 7 and 5 patients, respectively. In a second study [65], methotrexate has been used in 36 consecutive patients with recurrent active TED, previously treated with corticosteroids then stopped due to the occurrence of side effects. Two different weekly doses were administered depending on the weight of the patient $(7.5 \mathrm{mg}$ or $10 \mathrm{mg})$. There was a statistically significant improvement in 7-CAS at 12 months after treatment $(P<$ $0.0001)$. There was no significant change in visual acuity. Ocular motility disturbances improved significantly at 12 months $(P<0.001)$. There was no significant change in exophthalmos or eyelid position.

\section{Specific immunosuppressant}

1) Rituximab (RTX) is the better studied biological agent in TED. It is an anti-CD20 monoclonal antibody that targets $\mathrm{CD} 20$ on B cells and its precursors [66]. A randomised controlled trial in Europe comparing RTX to IV methylprednisolone in active moderate-severe TED supports effectiveness and disease-modifying effects with $100 \%$ response rate, no reactivation of TED at 24 weeks and less rehabilitative surgery required at 76 weeks [67]. A controlled trial in North America comparing RTX to placebo did not show a significant difference in the improvement of disease activity at 24 and 52 weeks, and there were more moderate-to-severe adverse events in the rituximab group [68]. The conflicting results from the rituximab RCTs could be related to small sample sizes and require clarification with larger controlled studies [66]. Perhaps the most important implications of both trials are that the earlier you treat, the greater the chance of immunosuppression being successful, and that much lower doses of rituximab might be equally effective and are probably better tolerated [69]. However, in both studies patients receiving RTX experienced, from $80 \%$ up to $85 \%$ of cases, adverse events, which were minor and easily reversible in the majority of cases, but 4 patients (16\% -combining the two series) overall developed dysthyroid optic neuropathy. It is hypothesised that the patients who developed dysthyroid optic neuropathy when given RTX had subclinical dysthyroid optic neuropathy already, and that rituximab induced a massive release of cytokines, known ascytokine-release syndrome that, caused further acute swelling of orbital tissues, thereby compressing the optic nerve [66]. Indeed, 6 cases of optic neuropathy, successfully treated with RTX, have been described [70], however failure of RTX was reported in one patient whose Graves' ophthalmopathy (GO) progressed to acute CON [71] and in one who already had CON [72] and failed to improve on RTX despite achieving peripheral B cell depletion. 
2) Tocilizumab (TCZ), a recombinant humanised monoclonal antibody against the IL- 6 receptor, that binds both soluble and membrane-bound forms of the receptor. IL- 6 is a pleiotropic cytokine secreted by several different cell types including $\mathrm{T}$ cells, macrophages, fibroblasts, osteoblasts and endothelial cells. It plays an important role in B cell activation and the development of antibody-producing plasma cells. Hence TCZ may reduce memory B cells and, eventually reduce immunoglobulin levels. It is mainly used in treatment of severe rheumatoid arthritis and juvenile idiopathic arthritis, has been trialled in 18 patients with active TED refractory to intravenous steroids. TCZ significantly improved clinical activity score in all patients and disease activity remained stable up to 27 months after infusion; improvement in proptosis, (72\%), extraocular motility, (83\%), and diplopia (54\%) were also noted [73]. A recent report showed a favourable response using TCZ even in severe vision threatening TED [74]. A double-masked randomised clinical trial, in patients with moderate-tosevere corticosteroid-resistant TED has been recently published. Randomisation was to either $8 \mathrm{mg} / \mathrm{kg}$ body weight TCZ or placebo administered intravenously at weeks $0,4,8$, and 12, and follow-up for an additional 28 weeks. The authors reported a significant difference in the proportion of patients achieving a CAS $<3$ and exophthalmos size change from baseline in patients treated with tocilizumab [75].

3) Etanercept (ETN) a TNF-alpha receptor blocker, has been found to improve the clinical activity score significantly for those suffering from mild-to-moderate TED, thus working more in terms of activity (i.e., clinical activity score) than severity of disease, in 10 consecutive patients, however $30 \%$ had recurrence of TED activity after treatment cessation [76].

4) Adalimumab ( $A D A)$ a fully human monoclonal antibody against TNF, may control prominent inflammatory symptoms, as noted in a small sample observer blinded. A case series showed improvement in an inflammatory score in $50 \%$ patients given adalimumab, indeed noted more in patients with high baseline scores for inflammation; no improvement of proptosis or motility have been noted [77].

5) Infliximub (IFX) has been successfully used in one steroid and orbital decompression resistant patient with severe TED and compression of the optic nerve [78]. The efficacy of the IFX in severe steroid and surgical resistant TED has also been recently reported in 3 more cases, with a complete resolution after 3 doses, 1 month apart, of $5 \mathrm{mg}$ per $\mathrm{kg}$ body weight $[79,80]$.

6) Teprotumumab, a human monoclonal anti-body inhibitor of IGF-IR, whose efficacy and safety has been recently assessed in a double-masked, randomised, placebocontrolled trial in patients with active moderate-to-severe TED [81]. The primary end point was defined as a reduction of 2 points or more in the CAS and a reduction of $2 \mathrm{~mm}$ or more in proptosis at week 24 . Secondary end points, measured as continuous variables, included proptosis, the CAS, and results on the GO-specific quality-of-life questionnaire. Sixty-nine per cent of patients who received teprotumumab as compared with $20 \%$ patients who received placebo had a response at week $24(P<0.001)$. Differences between the groups increased at subsequent time points. The only drugrelated adverse event was hyperglycaemia in patients with diabetes. The authors conclude that a 24 -week course of teprotumumab therapy provided clinical benefit in patients with active, moderate-to-severe TED by reducing proptosis and the CAS and by improving the patients' quality of life. No major adverse effects have been reported.

\section{Conclusion and general recommendation}

Ocular findings of TED include eyelid retraction, proptosis and ocular motility disturbance with a wide spectrum of inflammatory signs and soft tissue congestion [82] and occasionally vision loss from CON. Severe proptosis [83], ocular motility restriction [84] and eye-lid retraction may lead to a corneal breakdown, which together with CON represents an emergency. The grading of the soft tissue changes and the inflammatory symptoms and signs, defined as 'disease activity', can be assessed by using clinical activity score (CAS) criteria or vision, inflammation, strabismus, and appearance (VISA) classification [79]. The spectrum of ocular changes is graded as 'disease severity'. The range of TED treatment options varies depending upon severity, from topical palliative treatments including artificial tears, ointments or prisms, to immunosuppressive agents such as steroids, RT and surgical decompression in more severe cases.

Steroid therapy remains the first line therapy for moderate/severe and severe vision threatening TED. Since it was first introduced in 1955, many studies have tested its safety and efficacy, leading to a general consensus about the administration protocol and providing knowledge about the proper use, particularly the need to remain below a certain safe threshold, of the overall amount given [69]. However, the use of steroids has shown some limitations: the relapses of TED after completion of treatment account for about $20 \%$ with additional risk of reactivation after decompression [49, 85]. In addition, the occurrence of sides effects may require the withdrawal of the therapy.

Recent evidences have suggested that steroids combined with Azathioprine or Cyclosporine may reduce the relapse of the disease in the long term and, cyclosporine particularly, might reduce the need for surgery $[58,62,80]$.

Radiotherapy has been advocated as second line treatment for severe TED, alone or in combination with the steroid. A common treatment regimen is $20 \mathrm{~Gy}$ in 10 
divided doses over a 2-week period. It has been suggested that orbital irradiation may reduce the likelihood of emergent surgical decompression or to increase the effectiveness of surgical decompression [86].

If steroids must be withdrawn for side effects or because the results are poor, patients can be commenced with an alternative immunosuppressive antimetabolite such as methotrexate, which can be prolonged for two years to prevent relapse of the TED, or mycophenolate [63, 65].

Tocilizumab seems to be effective for treatment of steroid-resistant patients with low incidence of complication $[73,75]$.

Rituximab should not replace steroids as the treatment of choice in active moderate-to-severe Graves' ophthalmopathy, but it can be tried in corticosteroid-resistant cases, although chances of a favourable response appear lower with longer disease duration since it seems that the earlier the rituximab is administered the better are the chances the patient responds. Eventually, the use of rituximab for optic nerve compression is controversial and seems to carry the risk of worsening or cause a de novo onset of CON $[66,69,80]$.

On the basis of existing data, each of the following biologic agents: etanercept, adalimumab, tocilizumab and teprotumumab, have shown to be effective in reduction of the inflammatory signs [82] with the possible advantage to prevent relapse of the disease. Teprotumumab seems to be very effective particularly in preventing the severity of disease progression. Infliximab might be preferred in severe TED resistant to steroids and decompression.

Summarising all the above-mentioned medications, which can be divided in nonspecific immunosuppressant, such as methotrexate and mycophenolate and the more recent biological agents, can be used as a second line therapy. These alternative therapies may be particularly effective in conditions: steroid side effects, steroid resistance or dependence or, eventually, during disease flare ups or late reactivation. In this latter case it is important to avoid an excess cumulative dose of steroids, which may lead to severe adverse effects. Cyclosporine and azathioprine can be used in combination as first line treatment. The actual incidence of adverse effects, particularly for the new immunosuppressant agents, has not been fully assessed yet, therefore further study is necessary to better address the risk/benefit ratio.

\section{Compliance with ethical standards}

Conflict of interest The authors declare that they have no conflict of interest.

Publisher's note: Springer Nature remains neutral with regard to jurisdictional claims in published maps and institutional affiliations.

\section{References}

1. Garrity JA, Bahn RS. Pathogenesis of graves ophthalmopathy: implications for prediction, prevention, and treatment. Am J Ophthalmol. 2006;142:147-53.

2. Khoo TK, Bahn RS. Pathogenesis of Graves' ophthalmopathy: the role of autoantibodies. Thyroid. 2007;17:1013-8.

3. Bahn RS. Autoimmunity and Graves' disease. Clin Pharmacol Ther. 2012;91:577-9.

4. Amsen D, Backer RA, Helbig C. Decisions on the road to memory. Adv Exp Med Biol. 2013;785:107-20.

5. Shlomchik MJ, Weisel F. Germinal center selection and the development of memory B and plasma cells. Immunol Rev. 2012;247:52-63.

6. Pieper K, Grimbacher B, Eibel H. B-cell biology and development. J Allergy Clin Immunol. 2013;131:959-71.

7. Yoshida T, Mei H, Dörner T, Hiepe F, Radbruch A, Fillatreau S, et al. Memory B and memory plasma cells. Immunol Rev. 2010;237:117-39.

8. Duddy M, Niino M, Adatia F, Hebert S, Freedman M, Atkins H, et al. Distinct effector cytokine profiles of memory and naive human B cell subsets and implication in multiple sclerosis. J Immunol. 2007;178:6092-9.

9. Nie Y, Waite J, Brewer F, Sunshine MJ, Littman DR, Zou YR. The role of CXCR4 in maintaining peripheral B cell compartments and humoral immunity. J Exp Med. 2004;200: $1145-56$

10. Cassese G, Arce S, Hauser AE, Lehnert K, Moewes B, Mostarac $\mathrm{M}$, et al. Plasma cell survival is mediated by synergistic effects of cytokines and adhesion-dependent signals. J Immunol. 2003;171:1684-90.

11. Yang D, Hiromatsu Y, Hoshino T, Inoue $Y$, Itoh $K$, Nonaka K. Dominant infiltration of $\mathrm{T}(\mathrm{H}) 1$-type $\mathrm{CD} 4+\mathrm{T}$ cells at the retrobulbar space of patients with thyroid-associated ophthalmopathy. Thyroid. 1999;9:305-10.

12. Förster G, Otto E, Hansen C, Ochs K, Kahaly G. Analysis of orbital $\mathrm{T}$ cells in thyroid-associated ophthalmopathy. Clin Exp Immunol. 1998;112:427-34.

13. Pappa A, Calder V, Ajjan R, Fells P, Ludgate M, Weetman AP, et al. Analysis of extraocular muscle-infiltrating T cells in thyroidassociated ophthalmopathy (TAO). Clin Exp Immunol. 1997;109:362-9.

14. de Carli M, D'Elios MM, Mariotti S, Marcocci C, Pinchera A, Ricci M, et al. Cytolytic T cells with Th1-like cytokine profile predominate in retroorbital lymphocytic infiltrates of Graves' ophthalmopathy. J Clin Endocrinol Metab. 1993;77:1120-4.

15. Hiromatsu Y, Yang D, Bednarczuk T, Miyake I, Nonaka K, Inoue Y. Cytokine profiles in eye muscle tissue and orbital fat tissue from patients with thyroid-associated ophthalmopathy. J Clin Endocrinol Metab. 2000;85:1194-9.

16. Aniszewski JP, Valyasevi RW, Bahn RS. Relationship between disease duration and predominant orbital T cell subset in Graves' ophthalmopathy. J Clin Endocrinol Metab. 2000;85:776-80.

17. McLachlan SM, Rapoport B. Breaking tolerance to thyroid antigens: changing concepts in thyroid autoimmunity. Endocr Rev. 2014;35:59-105.

18. Barbesino G, Tomer Y. Clinical review: Clinical utility of TSH receptor antibodies. J Clin Endocrinol Metab. 2013;98:2247-55.

19. Iyer S, Bahn R. Immunopathogenesis of Graves' ophthalmopathy: the role of the TSH receptor. Best Pract Res Clin Endocrinol Metab. 2012;26:281-9.

20. Feliciello A, Porcellini A, Ciullo I, Bonavolontà G, Avvedimento EV, Fenzi G. Expression of thyrotropin-receptor mRNA in healthy and Graves' disease retro-orbital tissue. Lancet. 1993;342: $337-8$. 
21. Heufelder AE, Dutton CM, Sarkar G, Donovan KA, Bahn RS. Detection of TSH receptor RNA in cultured fibroblasts from patients with Graves' ophthalmopathy and pretibial dermopathy. Thyroid. 1993;3:297-300.

22. Bahn RS, Dutton CM, Joba W, Heufelder AE. Thyrotropin receptor expression in cultured Graves' orbital preadipocyte fibroblasts is stimulated by thyrotropin. Thyroid. 1998;8:193-6.

23. Gerding MN, van der Meer JW, Broenink M, Bakker O, Wiersinga WM, Prummel MF. Association of thyrotrophin receptor antibodies with the clinical features of Graves' ophthalmopathy. Clin Endocrinol. 2000;52:267-71.

24. Tsui S, Naik V, Hoa N, Hwang CJ, Afifiyan NF, Sinha Hikim A, et al. Evidence for an association between thyroid-stimulating hormone and insulin-like growth factor 1 receptors: a tale of two antigens implicated in Graves' disease. J Immunol. 2008;181:4397-405.

25. Chitnis MM, Yuen JS, Protheroe AS, Pollak M, Macaulay VM. The type 1 insulin-like growth factor receptor pathway. Clin Cancer Res. 2008;14:6364-70.

26. Smith TJ, Hegedüs L, Douglas RS. Role of insulin-like growth factor-1 (IGF-1) pathway in the pathogenesis of Graves' orbitopathy. Best Pract Res Clin Endocrinol Metab. 2012;26:291-302.

27. Wang Y, Smith TJ. Current concepts in the molecular pathogenesis of thyroid-associated ophthalmopathy. Invest Ophthalmol Vis Sci. 2014;55:1735-48.

28. van Steensel L, Paridaens D, van Meurs M, van Hagen PM, van den Bosch WA, Kuijpers RW, et al. Orbit-infiltrating mast cells, monocytes, and macrophages produce PDGF isoforms that orchestrate orbital fibroblast activation in Graves' ophthalmopathy. J Clin Endocrinol Metab. 2012;97:E400-408.

29. Feldon SE, Park DJ, O'Loughlin CW, Nguyen VT, LandskronerEiger S, Chang D, et al. Autologous T-lymphocytes stimulate proliferation of orbital fibroblasts derived from patients with Graves' ophthalmopathy. Invest Ophthalmol Vis Sci. 2005;46:3913-21.

30. Kuriyan AE, Woeller CF, O'Loughlin CW, Phipps RP, Feldon SE. Orbital fibroblasts from thyroid eye disease patients differ in proliferative and adipogenic responses depending on disease subtype. Invest Ophthalmol Vis Sci. 2013;54:7370-7.

31. Hwang CJ1, Afifiyan N, Sand D, Naik V, Said J, Pollock SJ, et al. Orbital fibroblasts from patients with thyroid-associated ophthalmopathy overexpress CD40: CD154 hyperinduces IL-6, IL-8, and MCP-1. Invest Ophthalmol Vis Sci. 2009;50:2262-8.

32. Koumas L, Smith TJ, Phipps RP. Fibroblast subsets in the human orbit: Thy-1+ and Thy-1- subpopulations exhibit distinct phenotypes. Eur J Immunol. 2002;32:477-85.

33. Smith TJ, Koumas L, Gagnon A, Bell A, Sempowski GD, Phipps $\mathrm{RP}$, et al. Orbital fibroblast heterogeneity may determine the clinical presentation of thyroid-associated ophthalmopathy. J Clin Endocrinol Metab. 2002;87:385-92.

34. Lehmann GM, Feldon SE, Smith TJ, Phipps RP. Immune mechanisms in thyroid eye disease. Thyroid. 2008;18:959-65.

35. Turcu AF, Kumar S, Neumann S, Coenen M, Iyer S, Chiriboga P, et al. A small molecule antagonist inhibits thyrotropin receptor antibody-induced orbital fibroblast functions involved in the pathogenesis of Graves ophthalmopathy. J Clin Endocrinol Metab. 2013;98:2153-9.

36. Zhang L, Bowen T, Grennan-Jones F, Paddon C, Giles P, Webber $\mathrm{J}$, et al. Thyrotropin receptor activation increases hyaluronan production in preadipocyte fibroblasts: contributory role in hyaluronan accumulation in thyroid dysfunction. J Biol Chem. 2009;284:26447-55.

37. Smith TJ, Hoa N. Immunoglobulins from patients with Graves' disease induce hyaluronan synthesis in their orbital fibroblasts through the self-antigen, insulin-like growth factor-I receptor. J Clin Endocrinol Metab. 2004;89:5076-80.
38. van Zeijl CJ, Fliers E, van Koppen CJ, Surovtseva OV, de Gooyer ME, Mourits MP, et al. Thyrotropin receptor-stimulating Graves' disease immunoglobulins induce hyaluronan synthesis by differentiated orbital fibroblasts from patients with Graves' ophthalmopathy not only via cyclic adenosine monophosphate signaling pathways. Thyroid. 2011;21:169-76.

39. Kumar S, Nadeem S, Stan MN, Coenen M, Bahn RS. A stimulatory TSH receptor antibody enhances adipogenesis via phosphoinositide 3-kinase activation in orbital preadipocytes from patients with Graves' ophthalmopathy. J Mol Endocrinol. 2011;46:155-63.

40. Smith PJ, Wise LS, Berkowitz R, Wan C, Rubin CS. Insulin-like growth factor-I is an essential regulator of the differentiation of 3T3-L1 adipocytes. J Biol Chem. 1988;263:9402-8.

41. Zhao P, Deng Y, Gu P, Wang Y, Zhou H, Hu Y, et al. Insulin-like growth factor 1 promotes the proliferation and adipogenesis of orbital adipose-derived stromal cells in thyroid-associated ophthalmopathy. Exp Eye Res. 2013;107:65-73.

42. Hers I. Insulin-like growth factor-1 potentiates platelet activation via the IRS/PI3Kalpha pathway. Blood. 2007;110:4243-52.

43. Boney CM, Gruppuso PA, Faris RA, Frackelton AR. The critical role of Shc in insulin-like growth factor-I-mediated mitogenesis and differentiation in 3T3-L1 preadipocytes. Mol Endocrinol. 2000;14:805-13.

44. Rhen T, Cidlowski JA. Antiinflammatory action of glucocorticoids--new mechanisms for old drugs. N Engl J Med. 2005;353: 1711-23.

45. Dickinson J, Perros P. Thyroid-associated orbitopathy: who and how to treat. Endocrinol Metab Clin North Am. 2009;38:373-88. ix

46. Kahaly GJ, Pitz S, Hommel G, Dittmar M. Randomized, single blind trial of intravenous versus oral steroid monotherapy in Graves' orbitopathy. J Clin Endocrinol Metab. 2005;90:5234-40.

47. Aktaran S, Akarsu E, Erbağci I, Araz M, Okumuş S, Kartal M. Comparison of intravenous methylprednisolone therapy vs. oral methylprednisolone therapy in patients with Graves' ophthalmopathy. Int J Clin Pract. 2007;61:45-51.

48. Marcocci C, Bartalena L, Panicucci M, Marconcini C, Cartei F, Cavallacci G, et al. Orbital cobalt irradiation combined with retrobulbar or systemic corticosteroids for Graves' ophthalmopathy: a comparative study. Clin Endocrinol. 1987;27:33-42.

49. Bartalena L, Krassas GE, Wiersinga W, Marcocci C, Salvi M, Daumerie C, et al. Efficacy and safety of three different cumulative doses of intravenous methylprednisolone for moderate to severe and active Graves' orbitopathy. J Clin Endocrinol Metab. 2012;97:4454-63.

50. Marcocci C, Bartalena L, Tanda ML, Manetti L, Dell'Unto E, Rocchi R, et al. Comparison of the effectiveness and tolerability of intravenous or oral glucocorticoids associated with orbital radiotherapy in the management of severe Graves' ophthalmopathy: results of a prospective, single-blind, randomized study. J Clin Endocrinol Metab. 2001;86:3562-7.

51. Marcocci C, Watt T, Altea MA, Rasmussen AK, Feldt-Rasmussen U, Orgiazzi J, et al. Fatal and non-fatal adverse events of glucocorticoid therapy for Graves' orbitopathy: a questionnaire survey among members of the European Thyroid Association. Eur J Endocrinol. 2012;166:247-53.

52. Sisti E, Coco B, Menconi F, Leo M, Rocchi R, Latrofa F, et al. Age and dose are major risk factors for liver damage associated with intravenous glucocorticoid pulse therapy for Graves' orbitopathy. Thyroid. 2015;25:846-50.

53. Zang S, Ponto KA, Kahaly GJ. Clinical review: Intravenous glucocorticoids for Graves' orbitopathy: efficacy and morbidity. J Clin Endocrinol Metab. 2011;96:320-32.

54. Giotaki Z, Fountas A, Tsirouki T, Bargiota A, Tigas S, Tsatsoulis A. Adrenal reserve following treatment of Graves' orbitopathy with intravenous glucocorticoids. Thyroid. 2015;25:462-3. 
55. Gasińska T, Borowska A, Wichary H, Dec R. Effect of methylprednisolone pulse therapy with and without alendronate on biochemical markers of bone turnover in patients with Graves' ophthalmopathy. Pol Arch Med Wewn. 2012;122:341-7.

56. Bartalena L, Pinchera A, Marcocci C. Management of Graves' ophthalmopathy: reality and perspectives. Endocr Rev. 2000;21:168-99.

57. Prummel MF, Mourits MP, Berghout A, Krenning EP, van der Gaag R, Koornneef L, et al. Prednisone and cyclosporine in the treatment of severe Graves' ophthalmopathy. N Engl J Med. 1989;321:1353-9.

58. Meyer PA. Avoiding surgery for thyroid eye disease. Eye. 2006;20:1171-7.

59. Perros P, Weightman DR, Crombie AL, Kendall-Taylor P. Azathioprine in the treatment of thyroid-associated ophthalmopathy. Acta Endocrinol. 1990;122:8-12.

60. Rajendram R, Lee RW, Potts MJ, Rose GE, Jain R, Olver JM, et al. Protocol for the combined immunosuppression and radiotherapy in thyroid eye disease (CIRTED) trial: a multi-centre, double-masked, factorial randomised controlled trial. Trials. 2008;9:6.

61. Chalvatzis NT, Tzamalis AK, Kalantzis GK, El-Hindy N, Dimitrakos SA, Potts MJ. Safety and efficacy of combined immunosuppression and orbital radiotherapy in thyroid-related restrictive myopathy: twocenter experience. Eur J Ophthalmol. 2014;24:953-9.

62. Rajendram R, Taylor PN, Wilson VJ, Harris N, Morris OC, Tomlinson $\mathrm{M}$, et al. Combined immunosuppression and radiotherapy in thyroid eye disease (CIRTED): a multicentre, $2 \times 2$ factorial, double-blind, randomised controlled trial. Lancet Diabetes Endocrinol. 2018;6:299-309.

63. Ye X, Bo X, Hu X, Cui H, Lu B, Shao J, et al. Efficacy and safety of mycophenolate mofetil in patients with active moderate-to-severe Graves' orbitopathy. Clin Endocrinol (Oxf). 2017;86:247-55.

64. Rivera-Grana E, Lin P, Suhler EB, Rosenbaum JT. Methotrexate as a corticosteroid-sparing agent for thyroid eye disease. J Clin Exp Ophthalmol. 2015;6:1-6.

65. Strianese D, Iuliano A, Ferrara M, Comune C, Baronissi I, Napolitano P, et al. Methotrexate for the treatment of thyroid eye disease. J Ophthalmol. 2014;2014:128903.

66. Stan MN, Salvi M. MANAGEMENT OF ENDOCRINE DISEASE: Rituximab therapy for Graves' orbitopathy - lessons from randomized control trials. Eur J Endocrinol. 2017;176:R101-R109.

67. Salvi M, Vannucchi G, Currò N, Campi I, Covelli D, Dazzi D, et al. Efficacy of B-cell targeted therapy with rituximab in patients with active moderate to severe Graves' orbitopathy: a randomized controlled study. J Clin Endocrinol Metab. 2015;100:422-31.

68. Stan MN, Garrity JA, Carranza Leon BG, Prabin T, Bradley EA, Bahn RS. Randomized controlled trial of rituximab in patients with Graves' orbitopathy. J Clin Endocrinol Metab. 2015;100: $432-41$.

69. Wiersinga WM. Advances in treatment of active, moderate-tosevere Graves' ophthalmopathy. Lancet Diabetes Endocrinol. 2017;5:134-42.

70. Salvi M, Vannucchi G, Campi I, Beck-Peccoz P. Rituximab in the treatment of thyroid eye disease: science fiction? Orbit. 2009;28: $251-5$.
71. Krassas GE, Stafilidou A, Boboridis KG. Failure of rituximab treatment in a case of severe thyroid ophthalmopathy unresponsive to steroids. Clin Endocrinol. 2010;72:853-5.

72. Gess AJ, Silkiss RZ. Orbital B-lymphocyte depletion in a treatment failure of rituximab for thyroid eye disease. Ophthalmic Plast Reconstr Surg. 2014;30:e11-13.

73. Pérez-Moreiras JV, Alvarez-López A, Gómez EC. Treatment of active corticosteroid-resistant graves' orbitopathy. Ophthalmic Plast Reconstr Surg. 2014;30:162-7.

74. Sy A, Eliasieh K, Silkiss RZ. Clinical Response to Tocilizumab in Severe Thyroid Eye Disease. Ophthalmic Plast Reconstr Surg. 2017;33:e55-e57.

75. Perez-Moreiras JV, Gomez-Reino JJ, Maneiro JR, Perez-Pampin E, Romo Lopez A, Rodríguez Alvarez FM, et al. Efficacy of tocilizumab in patients with moderate to severe corticosteroid resistant Graves' orbitopathy: a randomized clinical trial. Am J Ophthalmol. 2018;195:181-90.

76. Paridaens D, van den Bosch WA, van der Loos TL, Krenning EP, van Hagen PM. The effect of etanercept on Graves' ophthalmopathy: a pilot study. Eye. 2005;19:1286-9.

77. Ayabe R, Rootman DB, Hwang CJ, Ben-Artzi A, Goldberg R. Adalimumab as steroid-sparing treatment of inflammatory-stage thyroid eye disease. Ophthalmic Plast Reconstr Surg. 2014;30:415-9.

78. Durrani OM, Reuser TQ, Murray PI. Infliximab: a novel treatment for sight-threatening thyroid associated ophthalmopathy. Orbit. 2005;24:117-9.

79. Strianese D. Update on Graves disease: advances in treatment of mild, moderate and severe thyroid eye disease. Curr Opin Ophthalmol. 2017;28:505-13.

80. Strianese D. Efficacy and safety of immunosuppressive agents for thyroid eye disease. Ophthalmic Plast Reconstr Surg. 2018;34(4S Suppl 1):S56-S59.

81. Smith TJ, Kahaly GJ, Ezra DG, Fleming JC, Dailey RA, Tang RA, et al. Teprotumumab for thyroid-associated ophthalmopathy. N Engl J Med. 2017;376:1748-61.

82. Mawn LA, Dolman PJ, Kazim M, Strianese D, Genol I, Chong KKL, et al. Soft tissue metrics in thyroid eye disease: an International Thyroid Eye Disease society reliability study. Ophthalmic Plast Reconstr Surg. 2018;34:544-46.

83. Bingham CM, Sivak-Callcott JA, Gurka MJ, Nguyen J, Hogg JP, Feldon SE, et al. Axial globe position measurement: a prospective multicenter study by the International Thyroid Eye Disease Society. Ophthalmic Plast Reconstr Surg. 2016;32:106-12.

84. Dolman PJ, Cahill K, Czyz CN, Douglas RS, Elner VM, Feldon S, et al. Reliability of estimating ductions in thyroid eye disease: an International Thyroid Eye Disease Society multicenter study. Ophthalmology. 2012;119:382-9.

85. Strianese D, Piscopo R, Elefante A, Napoli M, Comune C, Baronissi I, et al. Unilateral proptosis in thyroid eye disease with subsequent contralateral involvement: retrospective follow-up study. BMC Ophthalmol. 2013;13:21.

86. Grassi P, Strianese D, Piscopo R, Pacelli R, Bonavolontà G. Radiotherapy for the treatment of thyroid eye disease-a prospective comparison: Is orbital radiotherapy a suitable alternative to steroids? Ir J Med Sci. 2017;186:647-52. 